\title{
Evolução do sistema de transmissão de energia elétrica, após a crise energética de 2001
}

\section{Power transmission system evolution, after the 2001 energy crisis}

\author{
DOI: $10.46814 / \operatorname{lajdv3n1-030}$
}

Recebimento dos originais: 30/10/2020

Aceitação para publicação: 23/12/2020

\section{Humberto Rodrigues Macedo \\ Mestrado.}

Instituto Federal de Educação, Ciência e Tecnologia - Campus Palmas

Endereço: Quadra Ae 310 Sul Avenida Ns 10 S/N - Plano Diretor Sul, Palmas - TO, 77021-090

E-mail.: humberto.macedo@ifto.edu.br

\section{Kaisson Teodoro de Souza \\ Mestrado.}

Instituto Federal de Educação, Ciência e Tecnologia - Campus Palmas

Endereço: Quadra Ae 310 Sul Avenida Ns 10 S/N - Plano Diretor Sul, Palmas - TO, 77021-090

E-mail.: kaisson@ifto.edu.br

\section{RESUMO}

Dentre os elementos que constituem o sistema elétrico, a linha de transmissão é o elo fundamental para interligar as unidades geradoras e as unidades consumidoras de energia elétrica. O país utiliza o Sistema Interligado Nacional - SIN, que oferece vantagens de logística em relação ao transporte de energia elétrica, aproveitando a diversidade hidrológica e as características sazonais das regiões. Neste contexto, as linhas de transmissão passam a ter fundamental importância para o equilíbrio e a eficiência do sistema elétrico. A crise energética ocorrida em 2001 deixou clara a necessidade de maiores investimentos no setor elétrico, tanto na geração de energia, quanto no sistema de transmissão. A taxa média de crescimento das linhas de transmissão durante a década de 1990 não passou de 1,7\%. Após a crise de energia elétrica de 2001, conhecida como "apagão", as instituições do setor energético passaram por uma reestruturação e foram criadas novas instituições como o Comitê de Monitoramento do Setor Elétrico - CMSE e a Empresa de Pesquisa Energética - EPE. Estas instituições, incorporadas às já existentes, passaram a ter a missão de evitar novas crises, buscar a modicidade tarifária e a universalização da energia elétrica, dentre outras. A partir de 2001 foi constatado o aumento da taxa média de crescimento da oferta de transmissão em relação ao decênio anterior. A expansão da fronteira de geração para a região Norte prevista no Plano Decenal de Expansão de Energia 2010 - 2019 contribuiu para a criação de linhas de transmissão com extensões superiores a $2.000 \mathrm{~km}$. Ampliando consideravelmente o Sistema Interligado e modificando a integração eletroenergética no Brasil, sobretudo com a transmissão da energia gerada nos rios da bacia amazônica para as regiões Sudeste e Nordeste, e a utilização de novas tecnologias de transmissão.

Palavras-chave: Crise Energética, Expansão, Linhas de Transmissão.

\section{ABSTRACT}

Among the elements that make up the electrical system, the transmission line is the fundamental link to interconnect the generating units and the units that consume electrical energy. The country uses the National Interconnected System - SIN, which offers logistic advantages in relation to electric power transportation, taking advantage of the hydrological diversity and seasonal characteristics of the 
regions. In this context, transmission lines are of fundamental importance for the balance and efficiency of the electrical system. The energy crisis of 2001 made clear the need for greater investment in the electricity sector, both in power generation and transmission. The average growth rate of transmission lines during the 1990s was only 1.7\%. After the 2001 electricity crisis, known as the "blackout," institutions in the energy sector underwent restructuring and new institutions were created, such as the Comitê de Monitoramento do Setor Elétrico - CMSE (Electricity Sector Monitoring Committee) and the Empresa de Pesquisa Energética - EPE (Energy Research Company). These institutions, incorporated into the existing ones, began to have the mission of avoiding new crises, seeking tariff modicity and the universalization of electric power, among others. Since 2001 the average growth rate of transmission supply has increased compared to the previous decade. The expansion of the generation frontier to the Northern region foreseen in the 10-year Plan for Energy Expansion 2010 - 2019 contributed to the creation of transmission lines with extensions of more than $2,000 \mathrm{~km}$. It considerably expanded the Interconnected System and modified the electrical energy integration in Brazil, especially with the transmission of energy generated in the rivers of the Amazon basin to the Southeast and Northeast regions, and the use of new transmission technologies.

Keywords: Energy Crisis, Expansion, Transmission Lines.

\section{INTRODUÇÃO}

A crise do setor elétrico decretada oficialmente em 2001, devido à falta de investimentos no setor elétrico e a escassez de chuvas mostraram a fragilidade do sistema elétrico brasileiro, tornandose evidente a necessidade de intervenção estrutural no setor e uma mudança no modelo de gestão do sistema elétrico. Assim foram criadas novas instituições com a finalidade de expandir, ampliar e reforçar a rede básica do sistema interligado nacional, visando afastar o risco de novas crises no setor elétrico (ANEEL, 2013).

$\mathrm{Na}$ última década tem-se observado uma mudança no mapa do setor elétrico do país, como a ampliação do parque energético, em especial da região Norte, influenciada principalmente pela demanda cada vez mais crescente por energia elétrica. Usinas de grande porte que estão sendo instaladas na região amazônica constituem a nova fronteira hidrelétrica nacional e irão interferir não apenas na dimensão do sistema de geração, mas também no perfil de transmissão de energia elétrica em todo o país.

Neste cenário, a necessidade de transmitir grandes blocos de energia por distâncias cada vez maiores, a exemplo da região Norte para as regiões centro-sul do país, através de linhas de transmissão que ultrapassam os $2.000 \mathrm{~km}$ de extensão contribui para a importância de estudos relacionados com a eficiência e o desenvolvimento novos modelos de linhas de transmissão.

O objetivo deste trabalho é analisar o comportamento do segmento de transmissão de energia elétrica frente às mudanças do cenário energético nacional nas últimas décadas. Para realizar tal estudo 
utilizou-se a crise no setor elétrico em 2001 como marco inicial e a análise da expansão da oferta de transmissão após a crise.

\section{MATERIAL E MÉTODOS}

A pesquisa foi realizada nos sítios das instituições do setor elétrico como: ANEEL, ONS, EPE, MME, entre outros, analisando os relatórios por eles emitidos. Também foram utilizados trabalhos acadêmicos e livros relacionados com o tema em questão. Todas as informações colhidas foram analisadas, a fim de comparar e avaliar o setor de geração e transmissão de energia elétrica após a crise energética de 2001.

\section{EXPANSÃO DO SISTEMA INTERLIGADO DE TRANSMISSÃO APÓS A CRISE ENERGÉTICA DE 2001}

A partir dos dados de expansão do SIN fornecidos pela ELETROBRAS e pelo ONS, foi elaborado o gráfico, mostrado na Figura 1, o qual faz uma comparação com a expansão das linhas de transmissão, antes e após o ano da crise do setor elétrico em 2001.

Figura 1 - Expansão das linhas de transmissão de 1990 a 2012.

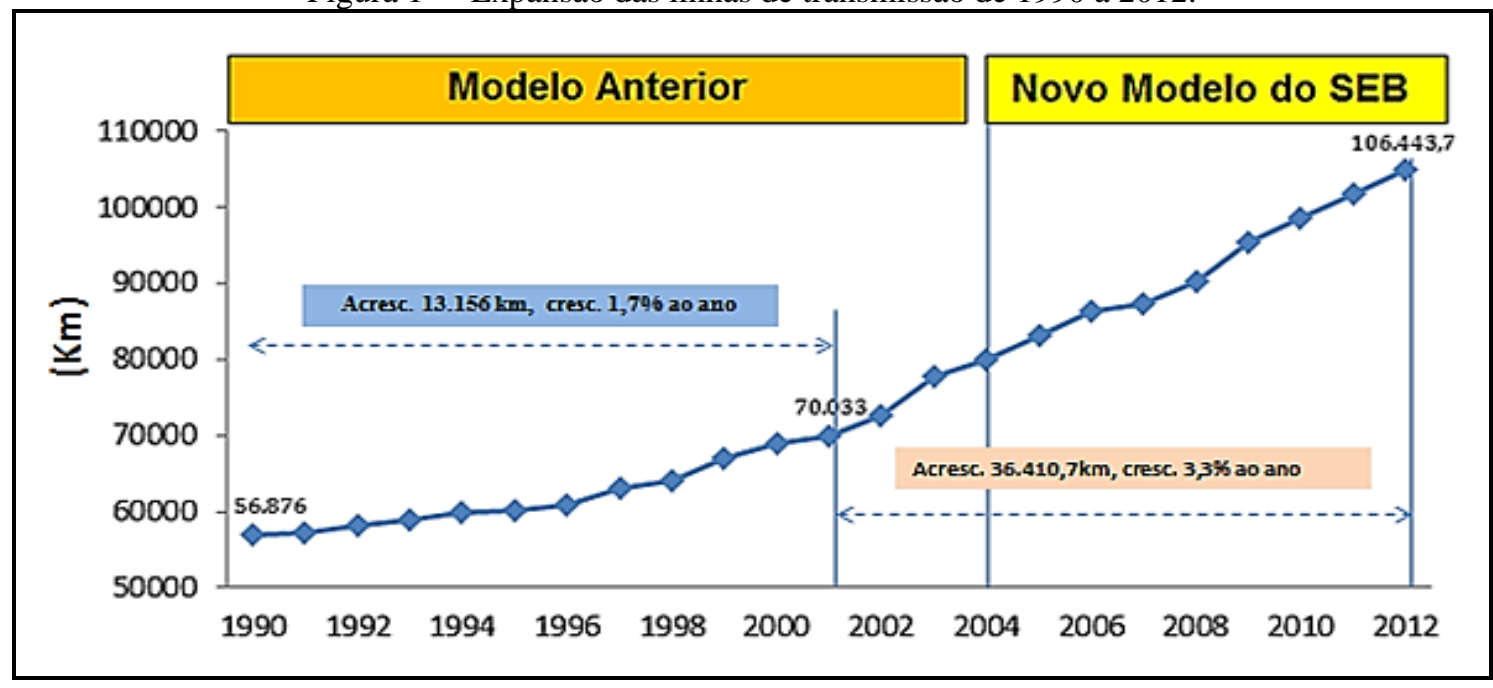

Fonte: Elaborado pelos autores - Dados Relatórios Eletrobras/ONS (2014).

Portanto, no período de 11 anos, compreendido entre 1990 a 2001, o sistema de transmissão brasileiro foi ampliado em $13.156 \mathrm{~km}$, a uma taxa de crescimento média de 1,7\% ao ano. Para um mesmo período de 11 anos, entre 2001 e 2012, o SIN foi ampliado em 36.410,7 km, uma taxa de crescimento médio de 3,3\% ao ano (SANTOS; MACEDO, 2014).

A capacidade de transformação do SIN, o qual leva em consideração a capacidade e potência das linhas de transmissão, é indicador de grande relevância. O novo modelo de legislação, a 
necessidade de reforços e as ampliações no SIN, com a finalidade de evitar novas crises, foram fatores que impulsionaram a expansão da capacidade de transformação.

Portanto, observa-se através da Figura 2 que a partir da crise em 2001 até o ano de 2012 foram adicionados mais de 100.000 MVA ao SIN. Assim o sistema interligado, além de ampliar sua área territorial e diminuir as regiões isoladas, também amplia sua capacidade de escoar os blocos de energia.

Também destacamos a falta de monitoração nas obras de construção de linhas de transmissão como um dos motivos que contribuíram para que o crescimento da capacidade de transformação não superasse o demonstrado na Figura 2.

Figura 2 - Evolução da capacidade de transformação do SIN.

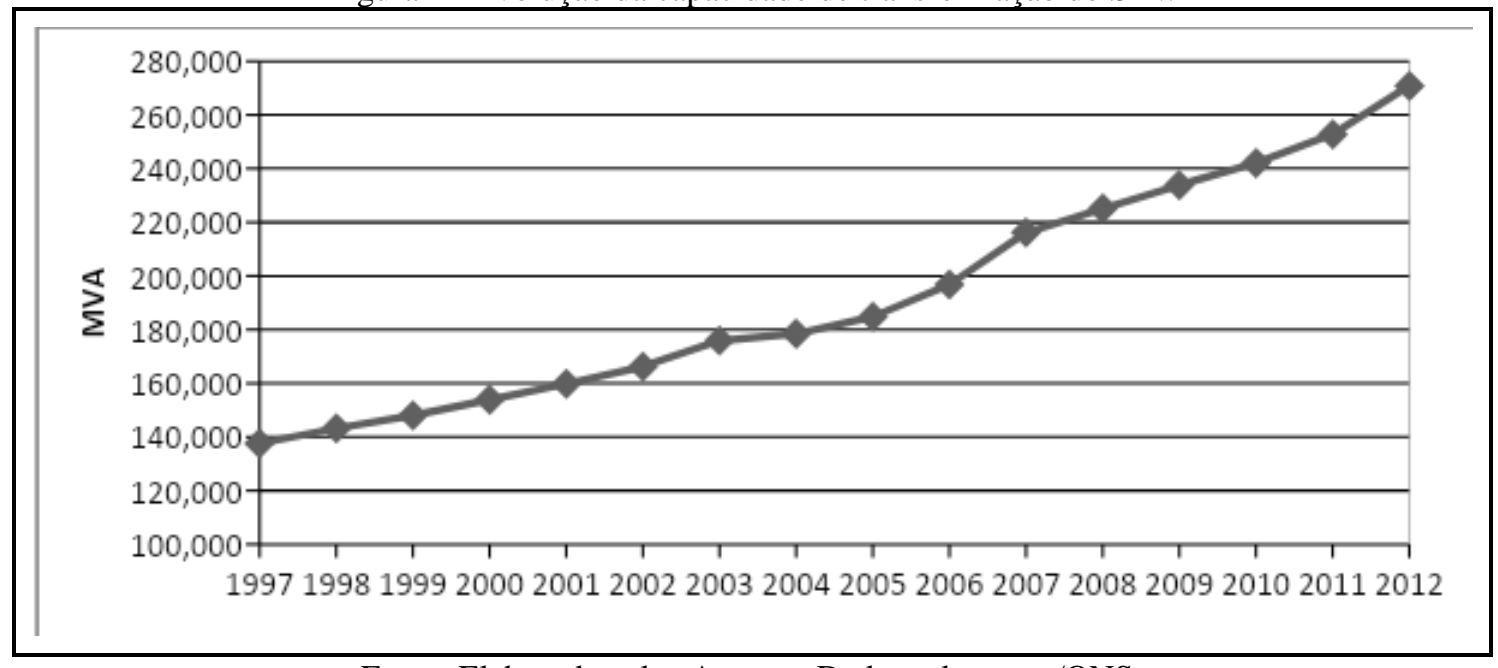

Fonte: Elaborada pelos Autores. Dados relevantes/ONS.

Em função do modelo energético adotado pelo Brasil privilegiando a matriz energética hidráulica e o esgotamento dessas fontes próximas aos grandes centros consumidores, região centrosul, fez com que a fronteira de produção de energia elétrica se expandisse em direção a região norte do país, conforme a figura 3, tornando o setor elétrico nacional cada vez mais dependente de um sistema de transmissão eficiente e confiável.

Para o transporte desta energia por distâncias superiores a $2.000 \mathrm{~km}$, está sendo considerada a viabilidade de tecnologias “ditas” como não convencionais de transmissão. 
Figura 3 - Evolução da capacidade instalada do SIN de 2009 a 2019, considerada a importação de Itaipu proveniente da potência contratada do Paraguai.

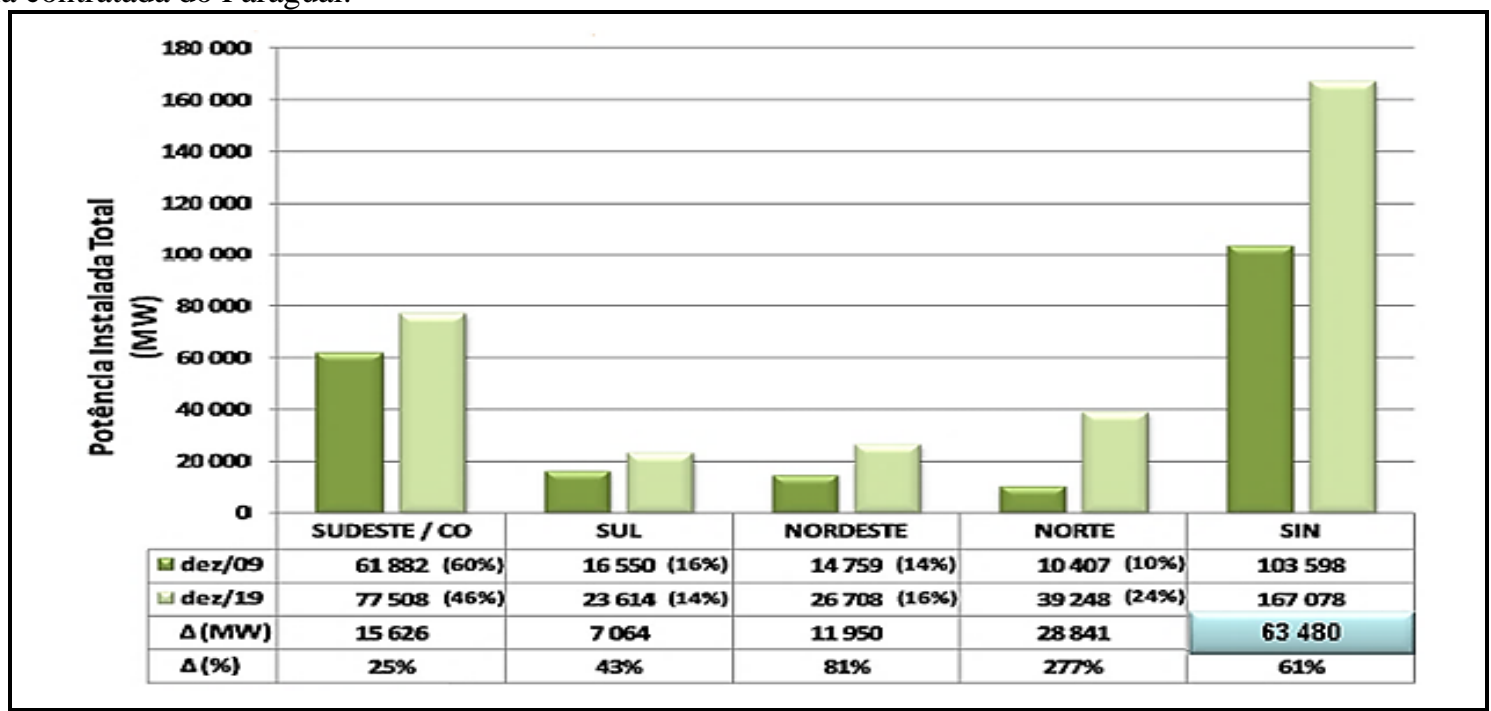

Fonte: PDE (2022).

O mapa do sistema de transmissão de 2001 e 2012 ilustrado na Figura 4 permite observar a tendência de expansão do SIN para a região Norte, a diminuição dos sistemas isolados, e o benefício da exportação da energia excedente para a região Sudeste e Nordeste, que tradicionalmente sofrem com a escassez de chuvas, contrastando com as cheias dos rios da região Norte.

Em 26 de novembro de 2013 foi colocada em operação a primeira linha do complexo do Rio Madeira com $2.385 \mathrm{~km}$ em $\pm 600 \mathrm{kVcc}$. Esta linha cruza o Brasil de Norte a Sudeste ligando a subestação coletora Porto Velho, em Rondônia, à subestação Araraquara 2, em São Paulo, sendo a mais extensa linha de transmissão em corrente contínua do mundo. É apenas a primeira de duas linhas previstas, e que escoarão a energia de $3.150 \mathrm{MW}$ gerados pelas usinas hidrelétricas de Jirau e Santo Antônio no Rio Madeira (TRACTEBEL, 2014). 
Figura 5- Evolução do mapa de transmissão e integração eletroenergética.

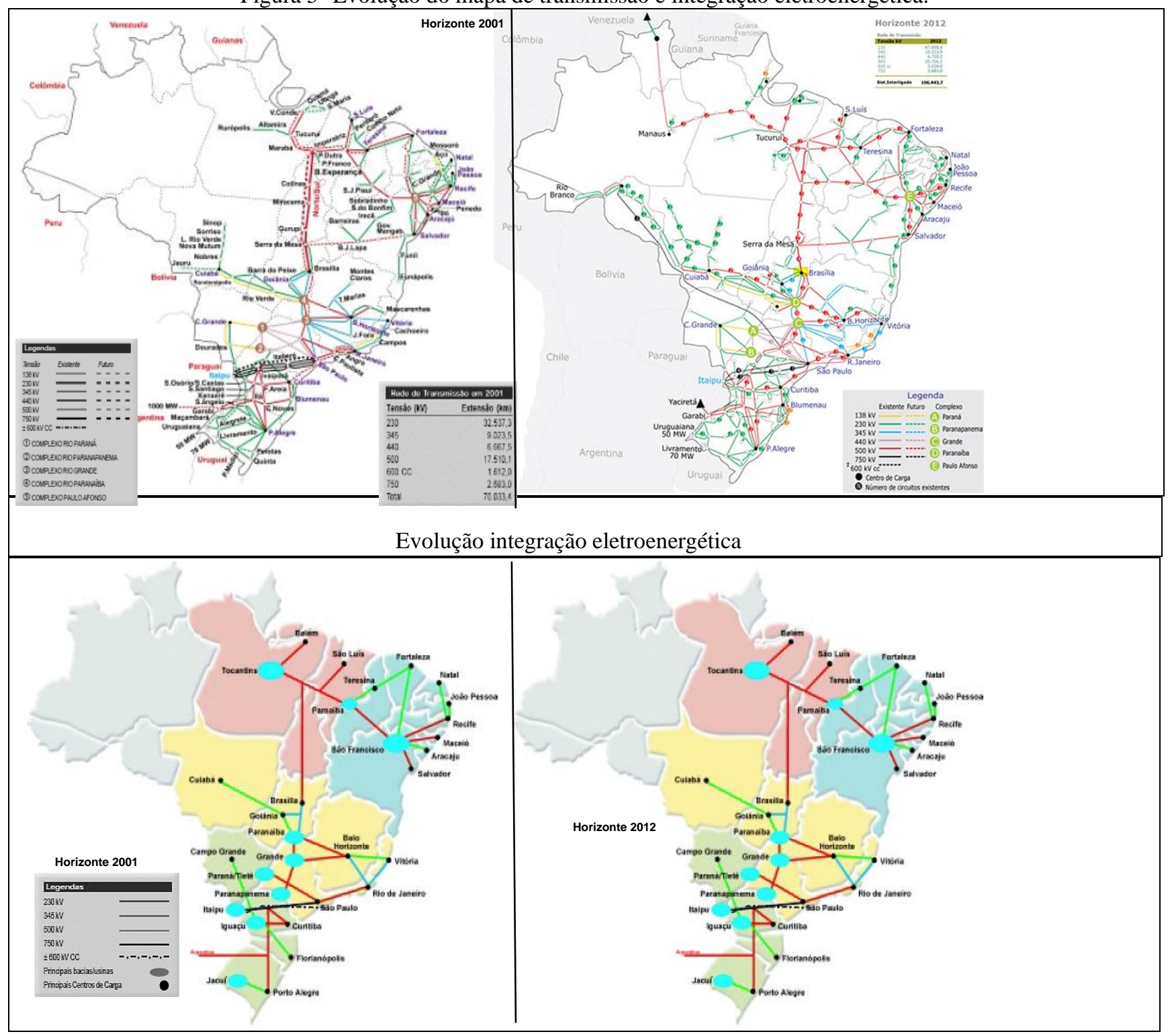

Fonte: ONS. Dados relevantes $(2001,2012)$.

\section{PERSPECTIVAS DE INVESTIMENTO E EXPANSÃO DO SISTEMA DE TRANSMISSÃO BRASILEIRO}

O crescimento apontado no PDE 2013 - 2022 sugere investimentos em linhas de transmissão e subestações transmissoras neste período para acompanhar o crescimento da demanda, assim como a oferta de energia elétrica para o decênio 2013 - 2022.

A EPE estima uma evolução física no sistema de transmissão de $47.732 \mathrm{~km}$ considerando o período 2012 - 2021, com a participação muito grande das linhas de $500 \mathrm{kV}$ e de $7.325 \mathrm{~km}$ de linhas de transmissão em corrente contínua na tensão de \pm 800 kVcc, conforme Tabela1 (PDE - 2021, 2012). 
Tabela 1 - Estimativa da evolução física das linhas de transmissão (km)

\begin{tabular}{|c|c|c|c|c|c|c|c|c|}
\hline Tensão & $\pm 800 \mathrm{kV}$ & $\begin{array}{l}750 \\
\mathrm{kV} \\
\end{array}$ & $\pm 600 \mathrm{kV}$ & $\begin{array}{l}500 \\
\mathrm{kV}\end{array}$ & $\begin{array}{l}440 \\
\mathrm{kV}\end{array}$ & $\begin{array}{l}345 \\
\mathrm{kV}\end{array}$ & $230 \mathrm{kV}$ & TOTAL \\
\hline Existente em 2011 & 0 & 2.683 & 1.612 & 34.851 & 6.679 & 10.063 & 45.349 & 101.237 \\
\hline $\begin{array}{l}\text { Evolução 2012- } \\
2021\end{array}$ & 7.325 & 0 & 4.750 & 26.889 & 113 & 337 & 8.318 & 47.732 \\
\hline $\begin{array}{l}\text { Evolução 2012- } \\
2016\end{array}$ & 0 & 0 & 4.750 & 21.547 & 47 & 337 & 7.874 & 34.555 \\
\hline $\begin{array}{l}\text { Evolução 2012- } \\
2021\end{array}$ & 7.325 & 0 & 0 & 5.342 & 66 & 0 & 444 & 13.177 \\
\hline Estimativa 2021 & 7.325 & 2.683 & 6.362 & 61.740 & 6.792 & 10.400 & 53.668 & 148.969 \\
\hline
\end{tabular}

Para o período 2011 - 2020, considerando os valores acumulados e as instalações já licitadas que entrarão em operação neste período, o valor dos investimentos chega a $\mathrm{R} \$ 30$ bilhões em linhas de transmissão e $\mathrm{R} \$ 16,4$ bilhões em subestações. Se retirar desta conta os investimentos já licitados, ainda tem até o final do decênio, investimentos de $\mathrm{R} \$ 19$ bilhões em linhas de transmissão e $\mathrm{R} \$ 10$ bilhões em subestações (PDE - 2020, 2011).

A capacidade de transformação em MVA prevista para o período de 2012 - 2021 é de 78.336 MVA, assim a estimativa do PDE 2021 é que ao final do ano 2021 o SIN-Sistema Interligado Nacional, tenha uma capacidade total de 311.213 MVA (PDE 2021, 2012).

No Plano Decenal de Expansão 2021, os investimentos previstos anualmente em linhas de transmissão estão estimados em $\mathrm{R} \$ 36$ bilhões de reais conforme Figura 6 e para as subestações um valor aproximado de $\mathrm{R} \$ 19,5$ bilhões de reais, conforme Figura 7, incluindo as instalações já licitadas que entram em operação no período decenal e as expansões referentes à entrada de usinas eólicas neste período. Percebe-se que os maiores investimentos se concentram no período de 2012 a 2017, tanto em linhas de transmissão quanto em subestações (PDE - 2021, 2012).

Figura 6 - Estimativa dos investimentos em linhas de transmissão.

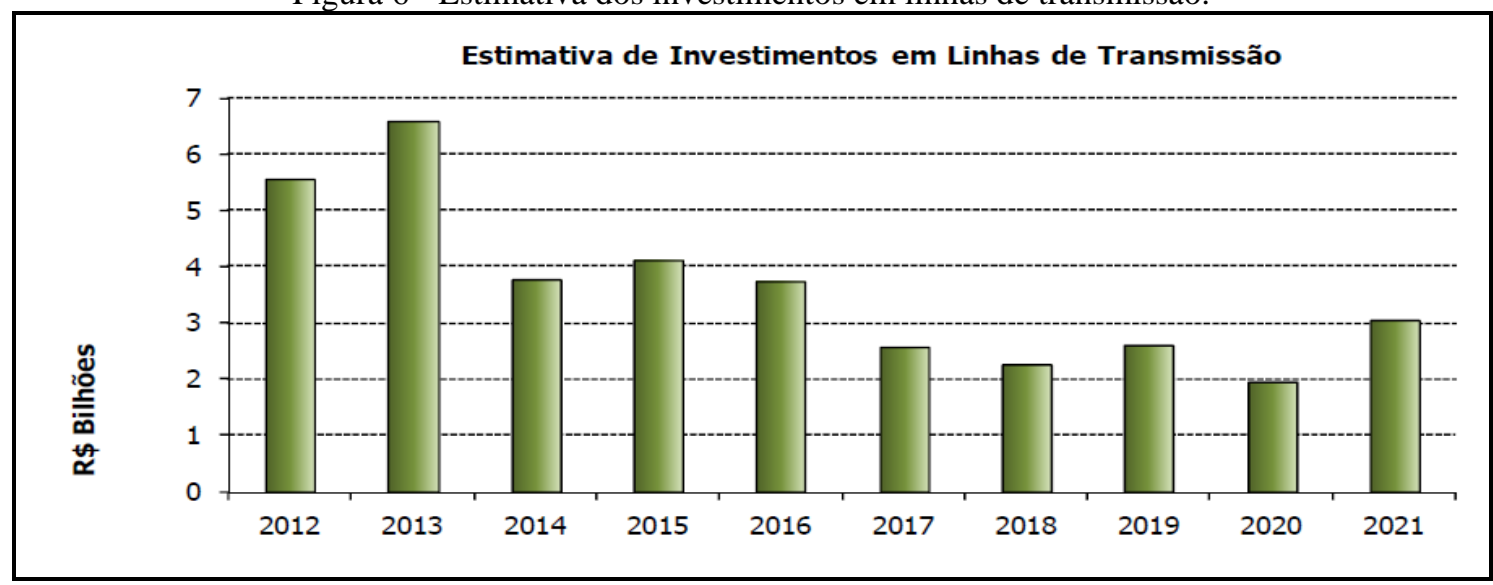

Fonte: PDE 2021. 
Figura 7 - Estimativa dos investimentos em subestação.

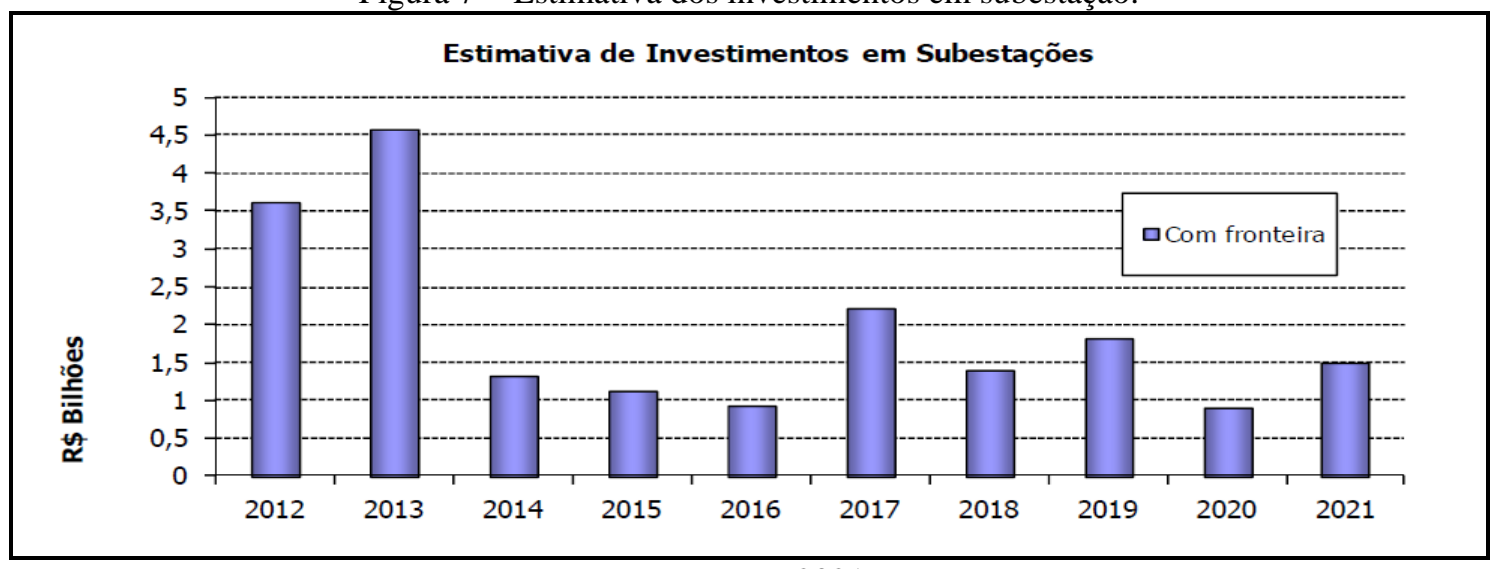

Fonte: PDE 2021.

Considerando os investimentos por níveis de tensão com o valor acumulado para o período 2012 - 2021, destaca -se os investimentos nas linhas de $500 \mathrm{kV}$ e $\pm 800 \mathrm{kVcc}$ e para acompanhar o avanço e a ampliação das linhas de transmissão será investido em subestações para o mesmo período o valor de $\mathrm{R} \$ 19,5$ bilhões, incluindo as instalações de fronteira, conforme Figura 8.

Figura 8 - Investimento em linhas de transmissão e subestação no período 2012 - 2021. (PDE, 2021).

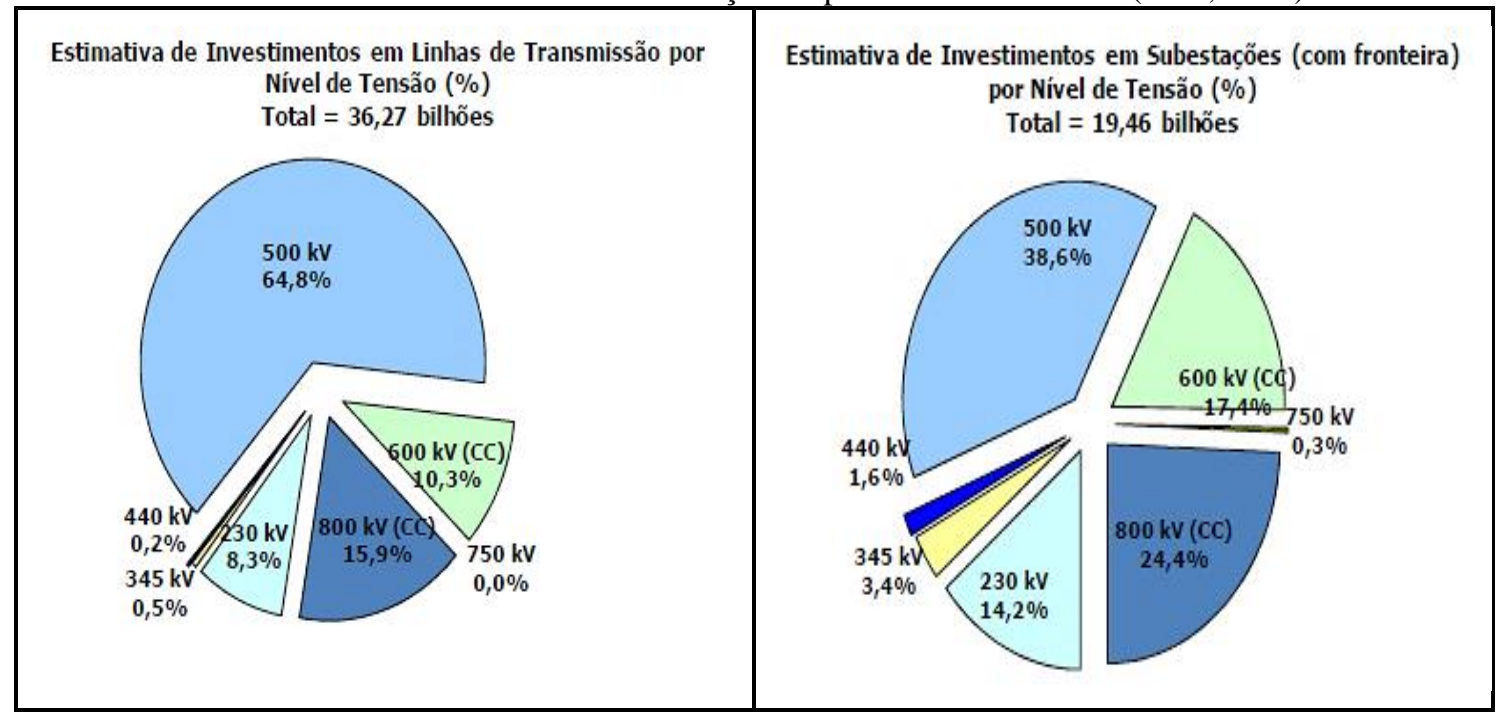

Entre os destaques do programa está o sistema de transmissão associado à usina hidrelétrica de Belo Monte, com dois bipolos, em tensão de \pm 800 kVcc, conectando a subestação de Xingu 500 kV (no Pará) a dois pontos de conexão na região sudeste, Estreito 500 kV (em Minas Gerais) e o Terminal Rio $500 \mathrm{kV}$ (no Rio de Janeiro). O empreendimento, iniciou a operação comercial do seu primeiro bipolo (Xingu-Estreito) em dezembro de 2017, tem uma extensão de $2.076 \mathrm{~km}$ e capacidade de escoar até 4.000 MW para a região Sudeste. O investimento total para implantação da linha de transmissão e das subestações associadas foi de R $\$ 5$ bilhões (CANAL ENERGIA, 2021). 
O maior investimento em linhas de transmissão será realizado na região Norte do país, onde existe abundância de recursos hídricos a serem explorados, e consequentemente maiores desafios para a construção de linhas de transmissão. Os investimentos por região em linhas de transmissão e subestações podem ser vistos na Tabela 2 (PET 2013 - 2017, 2013).

Tabela 2 - Investimentos em linhas de transmissão e subestações.

\begin{tabular}{l|l|l}
\hline \multicolumn{2}{l}{ INVESTIMENTO EM LINHAS DE TRANSMISSÃO } & R\$ BILHÕES \\
\hline REGIÃO & EXTENSÃO $(\mathbf{k m})$ & 1,5 \\
\hline Sudeste/Centro-Oeste & 2.705 & 0,5 \\
\hline Sul & 625 & 1,5 \\
\hline Nordeste & 2.418 & 4,9 \\
\hline Norte & 4.752 & $\mathbf{8 , 4}$ \\
\hline TOTAL & $\mathbf{1 0 . 5 0 0}$ & $\mathbf{R}$ BILHÕES \\
\hline INVESTIMENTO EM SUBESTAÇÃO/EQUIPAMENTOS & 2,8 \\
\hline REGIÃO & NOVAS SUBESTAÇÕES & 0,3 \\
\hline Sudeste/Centro-Oeste & 7 & 0,9 \\
\hline Sul & 3 & 2,2 \\
\hline Nordeste & 5 & $\mathbf{6 , 2}$ \\
\hline Norte & 6 &
\end{tabular}

Fonte: PET 2013-2017 (2013).

Podemos observar conforme a Figura 9 um avanço na participação das linhas de 500 kV ca e de $\pm 800 \mathrm{kV}$ cc, e ultrapassando a barreira de $140.000 \mathrm{~km}$ de linhas de transmissão no sistema interligado.

Figura 9 - Expansão das linhas de transmissão por níveis de tensão.

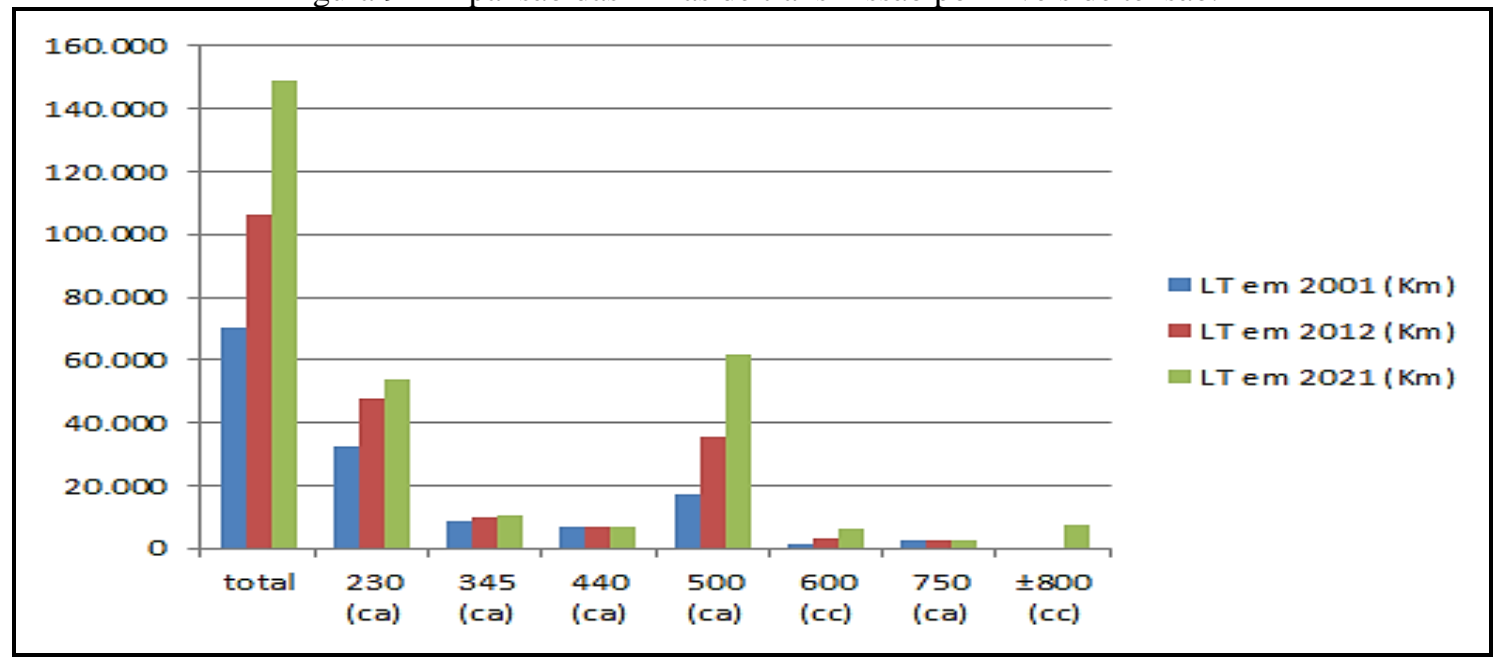

Fonte: Elaborado pelos autores - Dados Relatórios Eletrobras/ONS/PDE 2021. 


\section{A EXPANSÃO DA GERAÇÃO DE ENERGIA ELÈTRICA APÓS A CRISE DE 2001}

Embora a ampliação da diversificação da matriz elétrica fosse um dos objetivos e desafios das instituições responsáveis com os investimentos em novas fontes renováveis de energia, como a eólica e a solar, o carro chefe da geração brasileira ainda será por muitos anos a geração hídrica, devido fundamentalmente ao domínio das técnicas de construção de grandes usinas hidrelétricas e as características naturais do nosso país com grandes recursos hídricos a serem explorados, especialmente na região Norte, o que sugere também grandes investimentos em linhas de transmissão. Fato este que pode ser observado na Figura 10, ou seja, os investimentos em geração hídrica são fundamentais para a segurança do setor elétrico.

Figura 10 - Avanço anual da capacidade instalada de geração hídrica.

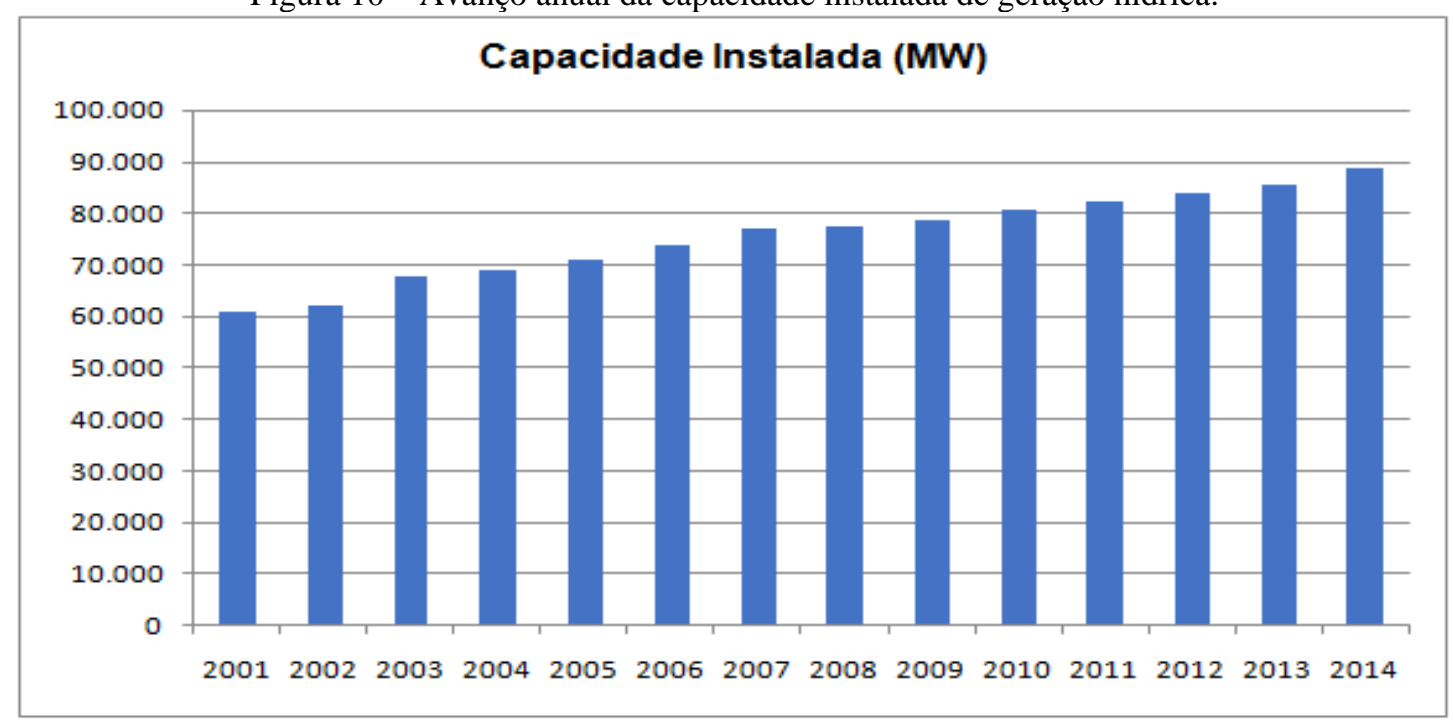

Elaborada pelos Autores. Dados do Banco de Informações da Geração de 2001 - 2014.

A participação das demais fontes de energia elétrica, incluindo a geração termelétrica, foi ampliada. Através dos dados pesquisados ano a ano, foi possível formatar o gráfico da Figura 11, que comprova que em 2014 a energia eólica passou a ser mais explorada. A energia solar ainda não teve destaque na matriz elétrica, embora esteja nas discussões e planejamentos futuros, especialmente na microgeração distribuída. 
Figura 11 - Expansão anual da geração hídrica, termelétrica e eólica de 2001 a 2014.

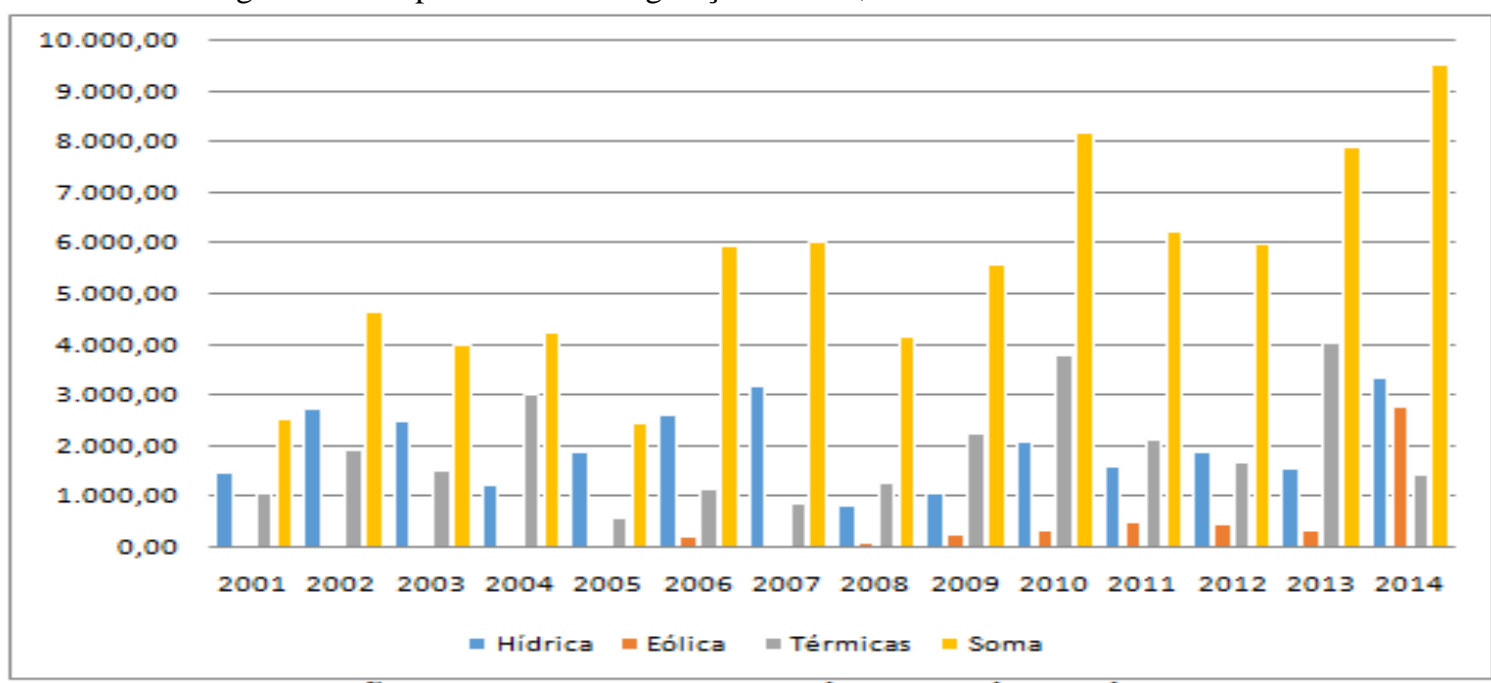

Eläborada pelos autores com dados do BIG de 2001 a 2014.

Importante informar que a geração termelétrica é evitada pelo governo, devido seu custo superior de geração, portanto são utilizadas como reforço no sistema, especialmente quando a demanda de energia não pode ser suprida pela geração da hidroeletricidade.

Para este mesmo período (2001 a 2014) foi levantado o consumo de eletricidade no SIN, o resultado pode ser observado na Figura 12.

Figura 12 - Consumo de eletricidade no Brasil. Macedo et al. (2015).

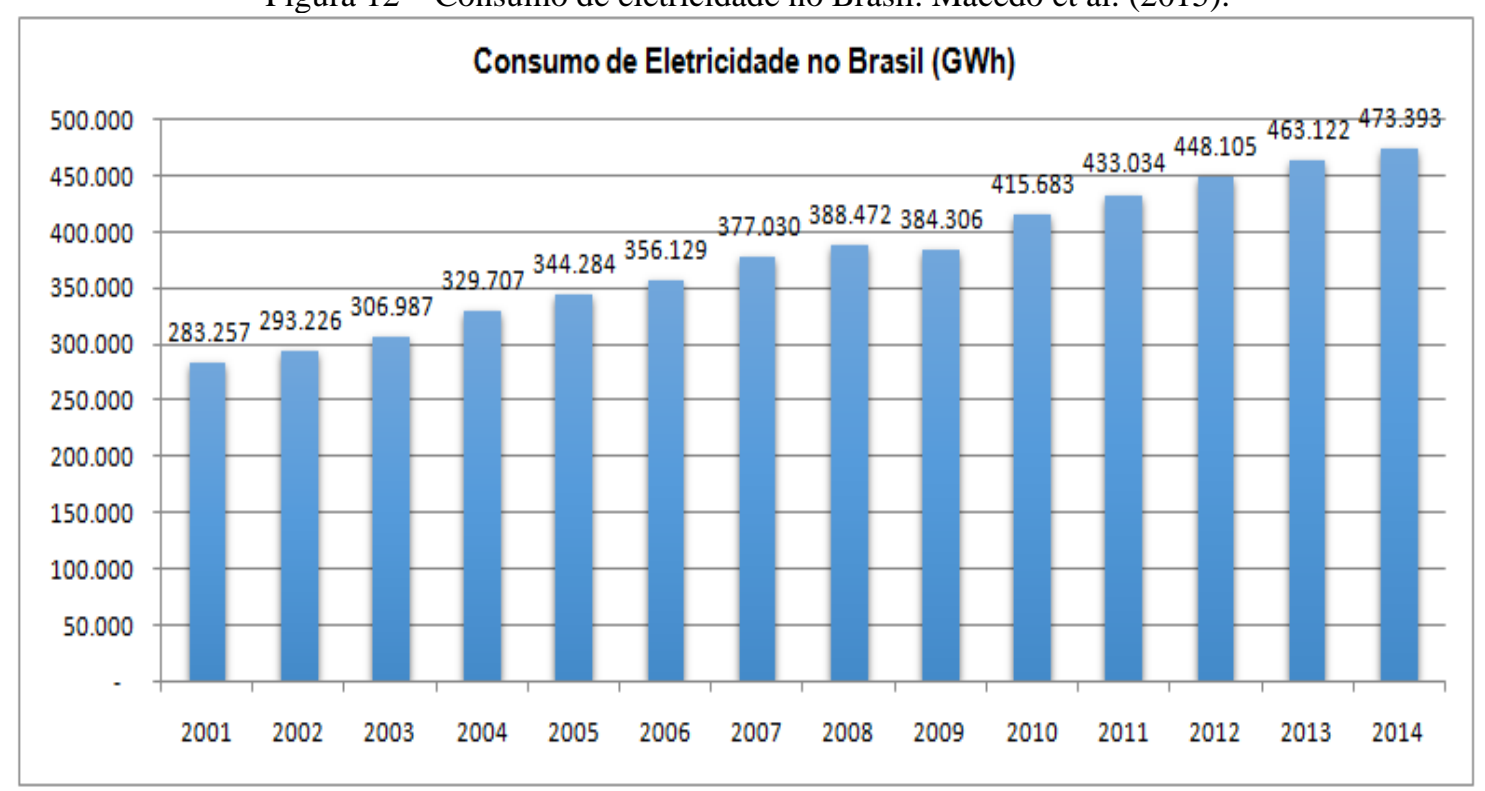

Dados do Balanço energético Nacional - BEN. Dados pesquisados de 2001 a 2014.

Como o sistema elétrico é composto pela geração, transmissão, distribuição e pelos consumidores de energia. Seria importante que as linhas de crescimento de cada setor fossem compatíveis, ou seja, o crescimento do consumo, da oferta de geração e transmissão fosse compatível 
e assim poderia demonstrar que o planejamento do setor elétrico foi realizado com eficiência e eficácia, especialmente pelas novas instituições que foram criadas como resposta à crise de 2001, Conforme observa-se pela Figura 13.

Figura 13 - Estrutura organizacional do setor elétrico implantado após a crise de 2001

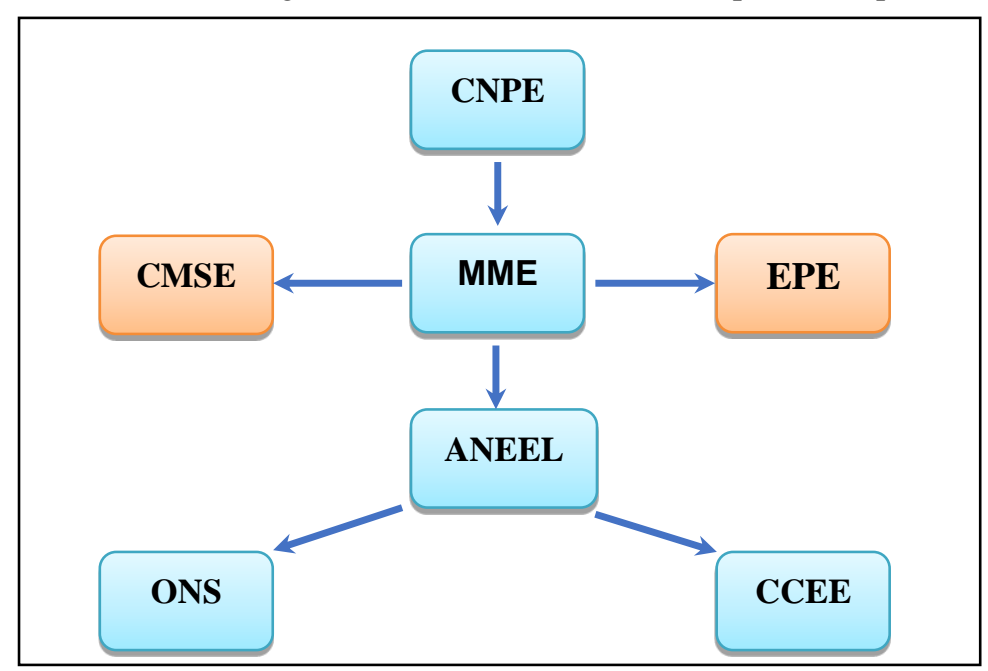

Fonte: ONS 2013.

Definições das principais instituições que compõem o atual setor elétrico brasileiro são demonstradas de acordo com a ANEEL (ANEEL, 2015).

- Ministério de Minas e Energia - MME: encarregado da formulação, planejamento e implementação de ações do Governo Federal no âmbito da política energética.

- Comitê de Monitoramento do Setor Elétrico - CMSE: constituído no âmbito do MME e sob sua coordenação direta, com a função precípua de acompanhar e avaliar permanentemente a continuidade e a segurança do suprimento eletro-energético.

- Empresa de Pesquisa Energética - EPE: empresa pública federal vinculada ao MME que tem por finalidade prestar serviços na área de estudos e pesquisas destinados a subsidiar o planejamento do setor energético.

- Conselho Nacional de Política Energética - CNPE: órgão de assessoramento da Presidência da República para formulação de políticas nacionais e diretrizes de energia, visando, dentre outros, o aproveitamento natural dos recursos energéticos do país, a revisão periódica da matriz energética e a definição de diretrizes para programas específicos.

- Agência Nacional de Energia Elétrica - ANEEL: autarquia vinculada ao MME, com finalidade de regular a fiscalização, a produção, transmissão, distribuição e comercialização de energia, em conformidade com as políticas e diretrizes do Governo Federal. A ANEEL detém os 
poderes: regulador e fiscalizador. Faz a intermediação entre os interesses dos consumidores, das empresas e do governo.

- Operador Nacional do Sistema Elétrico - ONS: pessoa jurídica de direito privado, sem fins lucrativos, sob a regulação e fiscalização da ANEEL, tem por objetivo executar as atividades de coordenação e controle da operação de geração e transmissão, no âmbito do SIN. O ONS é responsável pela operação física do sistema e pelo despacho energético centralizado.

- Câmara de Comercialização de Energia Elétrica - CCEE: pessoa jurídica de direito privado, sem fins lucrativos, sob a regulação e fiscalização da ANEEL, com finalidade de viabilizar a comercialização de energia elétrica no SIN. Administra os contratos de compra e venda de energia elétrica, sua contabilização e liquidação. A CCEE é responsável pela operação comercial do sistema.

Como parte da nossa pesquisa, foi elaborada pelos autores, a partir dos dados das instituições que regem o setor elétrico, a Figura 14, que demonstra claramente, pela entrada em operação dos investimentos em cada setor, a não uniformidade do crescimento anual.

Figura 14 - Taxa de crescimento anual em porcentagem da geração, transmissão e consumo de energia elétrica.

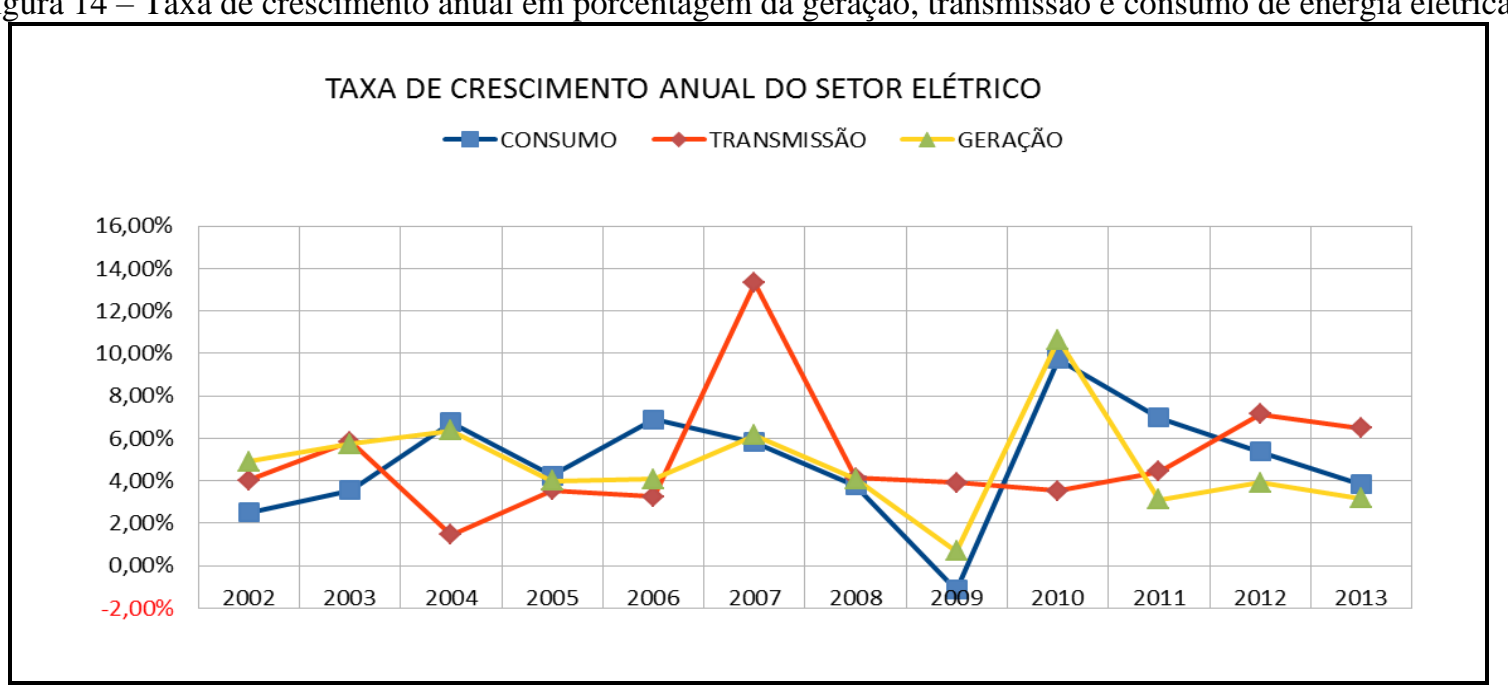

Macedo et al. (2015) com dados do ONS.

O gráfico da Figura 14 demonstra o crescimento dos setores de geração, consumo e transmissão. Destaca-se o ano de 2009 com quase zero de avanço na geração de energia em relação à geração de energia em 2008, felizmente este ano houve uma queda de consumo de energia elétrica de quase $2 \%$, em relação a transmissão de energia no SIN, neste mesmo ano de 2009, houve um acréscimo de $4 \%$ de potência em relação ao montante anterior. 
Em 2001, no período da crise, a matriz elétrica era composta apenas por hidráulica, térmica e nuclear, sendo a principal fonte a hidráulica que correspondia a 90\% da potência instalada. Passado mais de uma década da maior crise energética sofrida pelo país, observamos a passos lentos a diversificação da matriz. Atualmente o país continua dependendo da hidroeletricidade para geração de energia, contudo houve certa diversificação na matriz, que se expande gradualmente, como pode ser observado pela Figura 15.

Conforme pode ser constatado na Figura 15, as usinas hidrelétricas compõem a principal fonte de geração de eletricidade no país, com os empreendimentos em operação que somam uma potência instalada de 69,2\% do total gerado no país. As termelétricas, das quais se incluem as nucleares, correspondem a $28,7 \%$ do total de energia produzido, enquanto a participação das eólicas chegam a $1,9 \%$, as solares somam menos de $1 \%$.

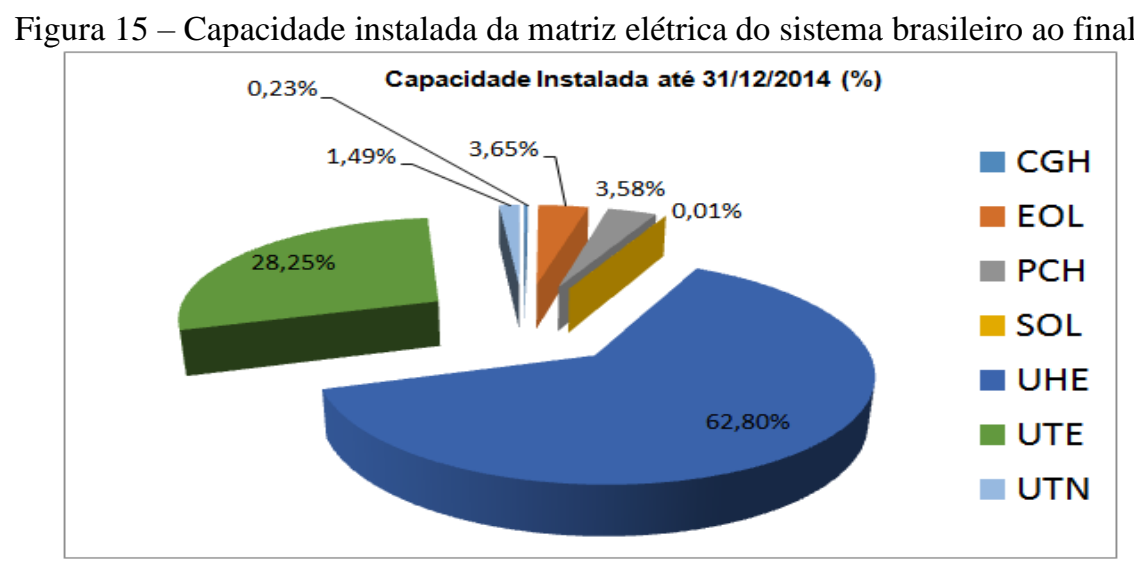

Fonte BIG 2014.

A Tabela 3 demonstra a quantidade de empreendimentos e a potência instalada com a porcentagem representativa do total da geração de energia elétrica brasileira para o ano de 2014, considerando todas as fontes de geração existentes.

Tabela 3 - Quantidade de empreendimentos, potência instalada e porcentagem do total da matriz elétrica do Brasil em 2014 , pelas diferentes fontes de geração. Dados da ANEEL - 2014.

$\begin{array}{cccc}\text { Modelo } & \text { Quantidade } & \text { Potência }(\mathbf{K W}) & \text { \% do total } \\ \text { UHE } & 196 & 81.801,32 & 63,9 \\ \text { PCH } & 477 & 4.669,84 & 3,7 \\ \text { CGH } & 449 & 275,195 & 0,2 \\ \text { UTE } & 1.824 & 36.756,81 & 28,7 \\ \text { UTN } & 2 & 1.990,00 & 1,6 \\ \text { EOL } & 117 & 2.441,18 & 1,9 \\ \text { UFV } & 87 & 6.209 & 0 \\ \text { Total } & 3.152 & 127.940 .555 & 100\end{array}$

UHE = Usina Hidrelétrica; PCH = Pequenas Centrais Hidrelétricas; CGH = Centrais de Geração Hidrelétrica; UTE = Usinas Termelétricas; UTN = Usinas Termonucleares; EOL = Geração Eólica; UFV = Usina Fotovoltaica. 


\section{CONCLUSÕES}

O histórico de atrasos em obras de transmissão e geração pode afetar o planejamento e a taxa de crescimento das linhas de transmissão. Cabe então a ANEEL impedir que empresas com atraso na entrega das obras de transmissão participem de novas licitações. Neste sentido cabe citar como ação a ser seguida em todos os novos leilões de transmissão, o Edital 02/2013, que possuía cláusula que impedia empresas que estivessem com grandes atrasos em obras de transmissão participassem do leilão (JORNAL DA ENERGIA, 2013).

Os atrasos na entrega de linhas de transmissão, como o ocorrido com a CHESF, FURNAS, (CHESF, 2014) deixam marcas e desconfianças na sociedade sobre a capacidade de planejamento confiável do sistema elétrico.

A crise do setor elétrico ocorrida em 2001 provocou mudanças significativas no setor elétrico. Embora a taxa média de crescimento da expansão da transmissão do SIN tenha quase dobrada, em relação à década de 1990, o novo modelo do setor elétrico não teve muito que comemorar após os dez anos de sua vigência, isto porque, em 2014, novamente se fala em risco de racionamento de energia elétrica, devido aos baixos níveis dos reservatórios das principais hidrelétricas do país, e pelo crescente aumento do consumo de energia elétrica, impulsionado pelo crescimento econômico do país.

Importante observar que durante o período de racionamento de energia elétrica, os consumidores, através de incentivos e metas, utilizaram de forma responsável e eficiente a energia elétrica disponível.

Portanto, os crescimentos homogêneos da transmissão e da geração devem acompanhar o consumo por eletricidade, além da diversificação da matriz elétrica. Com a pesquisa anual proposta pelos autores, podemos destacar as seguintes conclusões.

- Planejamento não foi bem sucedido em relação ao crescimento homogêneo da transmissão com a geração, ou seja, a premissa que a capacidade de geração deve crescer da mesma forma que a capacidade de transformação, a fim de que, não haja energia gerada sem poder ser transmitida e vice versa. O gráfico da Figura 14 demonstra que a transmissão em média teve crescimento superior maior que a geração, e que em alguns períodos o avanço do consumo foi superior ao da geração de energia.

- A estruturação do setor elétrico proposta em 2004, não pode ser considerada um sucesso, pois, ainda hoje, estamos falando em crise no setor elétrico.

- Houve um avanço em relação à dependência da matriz hidrelétrica, antes $90 \%$ em 2001 (ATLAS ANEEL, 2002), e chegando a cerca de 70\% em 2014 (ANEEL, 2014). 


\section{REFERÊNCIAS}

AGÊNCIA NACIONAL DE ENERGIA ELÉTRICA - ANEEL: Atlas de energia elétrica do Brasil. $1^{\mathrm{a}}$ edição: Brasília. ANEEL, 2002.

Disponível:<http://www.aneel.gov.br/arquivos/pdf/atlas_par1_cap1.pdf >. Acesso em: 11/08/2015. ANEEL - AGÊNCIA NACIONAL DE ENERGIA ELÉTRICĀ. Resoluções Normativas. Disponível em: <http://www.aneel.gov.br>. Acesso em: 7/11/2020.

BEN -EPE. Balanço energético nacional. Disponível em:

<http://www.epe.gov.br/Estudos/Paginas/default.aspx?CategoriaID=347> Acesso em: 12 ago 2015. BIG -ANEEL. Banco de informações de geração. Disponível em:

<http://www.aneel.gov.br/area.cfm?idArea=15> Acesso em: 28 jul 2020.

CHESF - COMPANHIA HIDRO ELÉTRICA DO SÃO FRANCISCO. Obras do sistema de transmissão têm atraso médio de 14 meses. Disponível em: < http://www.chesf.gov.br >. Acesso em: 23/01/2021.

EPE - EMPRESA DE PESQUISA ENERGÉTICA. INFORME À IMPRENSA: PET 2013-2017. Rio de Janeiro, 18/03/2013.

JORNAL DA ENERGIA. Aneel nega recurso de Furnas para participar do leilão de transmissão. Disponível em: <http://www.jornaldaenergia.com.br/>. Acesso em: 29/04/2020.

MACEDO, H.R; SOUZA, K.T.; MOURA, V.P.; SANTOS, R.A. A Expansão da Geração de

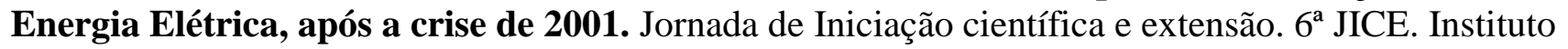
Federal do Tocantins - IFTO. ISSN: 2179-5645. 2015. Disponível em:

https://propi.ifto.edu.br/ocs/index.php/jice/6jice/paper/view/6946/3389. Acesso em 25 de janeiro de 2021.

MME/EPE. Plano Decenal de Expansão de Energia 2021. Brasília, 2012.

: Plano Decenal de Expansão de Energia 2022. Brasília, 2013.

ONS - OPERADOR NACIONAL DO SISTEMA. Dados Relevantes - Ano 2001. Disponível em: <http://www.ons.org.br>. Acesso em: 15/11/2020.

ONS - OPERADOR NACIONAL DO SISTEMA. Dados Relevantes 2001- 2014. Disponível em: <http://www.ons.org.br>. Acesso em: 04/01/2021.

SANTOS, S.C.; MACEDO, R.H. Expansão e perspectivas do sistema de transmissão brasileiro após a crise energética de 2001. 125 p. TCC - Instituto Federal de Educação, Ciência e Tecnologia do Tocantins, Palmas, 2014. 1 CD-ROM.

TRACTEBEL. Mais extensa linha de transmissão em corrente contínua no mundo é inaugurada. Disponível em: < http://www.tractebel-engineering-gdfsuez.com/>. Acesso em: $13 / 02 / 2014$.

AGÊNCIA NACIONAL DE ENERGIA ELÉTRICA - ANEEL: Acompanhamento da expansão da oferta de geração de energia elétrica. Acesso em: 12/07/2020.

CANAL ENERGIA. Operação do primeiro bipolo de Belo Monte inaugura LTs de 800 kV no país. Disponível em: <https://canalenergia.com.br/noticias/53046331/operacao-do-primeiro-bipolode-belo-monte-inaugura-lts-de-800-kv-no-pais>. Acesso em: 26/01/2021. 